\title{
Three-dimensional printing and in vitro evaluation of poly(3- hydroxybutyrate) scaffolds functionalized with osteogenic growth peptide for tissue engineering
}

\author{
Sybele Saska ${ }^{\mathrm{a}, *, 1}$, Luana Carla Pires ${ }^{\mathrm{b}, 1}$, Mariana Aline Cominotte ${ }^{\mathrm{b}}$, Larissa Souza Mendes ${ }^{\mathrm{a}}$, \\ Marcelo Fernandes de Oliveira ${ }^{c}$, Izaque Alves Maia ${ }^{c}$, Jorge Vicente Lopes da Silva ${ }^{c}$, \\ Sidney José Lima Ribeiro ${ }^{\mathrm{a}}$, Joni Augusto Cirelli ${ }^{\mathrm{b}, * *}$

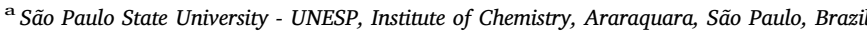 \\ ${ }^{\mathrm{b}}$ São Paulo State University - UNESP, School of Dentistry, Araraquara, São Paulo, Brazil \\ ${ }^{c}$ Centro de Tecnologia da Informação Renato Archer (CTI), Division of Three-dimensional Technologies, Campinas, São Paulo, Brazil
}

\section{A R T I C L E I N F O}

\section{Keywords:}

Three-dimensional printing

Poly(3-hydroxybutyrate)

Selective laser sintering

Scaffold

Osteogenic growth peptide

Tissue engineering

In vitro

\begin{abstract}
A B S T R A C T
Poly(3-hydroxybutyrate) (PHB) is a biodegradable and thermoprocessable biopolymer, making it a promising candidate for applications in tissue engineering. In the present study a structural characterization and in vitro evaluation were performed on PHB scaffolds produced by additive manufacturing via selective laser sintering (SLS), followed by post-printing functionalization with osteogenic growth peptide (OGP) and its C-terminal sequence OGP(10-14). The PHB scaffolds were characterized, including their morphology, porosity, thermal and mechanical properties, moreover OGP release. The results showed that SLS technology allowed the sintering of the PHB scaffolds with a hierarchical structure with interconnected pores and intrinsic porosity (porosity of $55.8 \pm 0.7 \%$ and pore size in the $500-700 \mu \mathrm{m}$ range), and good mechanical properties. Furthermore, the SLS technology did not change thermal properties of PHB polymer. The OGP release profile showed that PHB scaffold promoted a controlled release above $72 \mathrm{~h}$. In vitro assays using rat bone marrow stem cells showed good cell viability/proliferation in all the PHB scaffolds. Additionally, SEM images suggested advanced morphological differentiation in the groups containing osteogenic growth peptide. The overall results demonstrated that PHB biopolymer is potential candidate for 3D printing via SLS technology, moreover the OGP-containing PHB scaffolds showed ability to sustain cell growth to support tissue formation thereby might be considered for tissueengineering applications.
\end{abstract}

\section{Introduction}

Three-dimensional printing (3DP), also known as additive manufacturing (AM) is a current technology for manufacturing three-dimensional physical objects, layer-by-layer, from a digital model, directly from a computer aided design (CAD) file. This technology is a promising option for scaffolds manufacturing where the implants need to have anatomically accurate characteristics to defect, e.g. bone substitutes [1,2]. The 3D printing allows a better control of porosity, pore size, high geometric complexity, well-defined architecture as well as patient-specific implant designs than others established scaffold manufacturing methods [1]. Because of this versatility, this technology has been recently used in the biomedical area to manufacture scaffolds for replacement or reconstruction of complexes tissues or organs $[3,4]$.

There are different 3DP technologies such as selective laser sintering (SLS), stereolithography (SLA) and fused deposition modeling (FDM). They differ from each other by the materials that can be used and by the way the layers are deposited to create parts. In the SLS process, a $\mathrm{CO}_{2}$ laser beam writes part layers by agglutinating powder particles by heating. Resolution depends mainly on particles size and laser beam

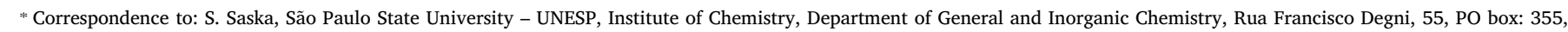
14800-900 Araraquara, São Paulo, Brazil.

** Correspondence to: J.A. Cirelli, São Paulo State University - UNESP, School of Dentistry, Department of Diagnosis and Surgery, Rua Humaitá, 1680, 1480-903 Araraquara, São Paulo, Brazil.

E-mail addresses: sysaska@gmail.com (S. Saska), luanacp@yahoo.com.br (L.C. Pires), marianaacominott@foar.unesp.br (M.A. Cominotte),

marcelo.oliveira@cti.gov.br (M.F. de Oliveira), izaque.maia@cti.gov.br (I.A. Maia), jorge.silva@cti.gov.br (J.V.L. da Silva), sidney@iq.unesp.br (S.J.L. Ribeiro), cirelli@foar.unesp.br (J.A. Cirelli).

${ }^{1}$ These authors contributed equally to this work. 
diameter. The interaction of the laser beam with the powder generates heating, which increases the temperature of the polymer close to the melting point leading to the fusion of their surfaces to form a solid mass, phenomenon known as sinterization $[5,6]$.

The powder processing and technologies, as SLS, have the advantage to manufacture scaffolds with greater controlled porosity and pore size than other conventional processes [5]. These and other architectural features, e.g. permeability, play a significant role in drug delivery systems and tissue regeneration [7]. In bone tissue engineering, the advantage of this technology is given by providing the control of fine features including interconnected porosity and no contamination issues related to any second material for supporting structures [4].

Thermoplastic polymers have been widely used in the SLS technology. Among these polymers, polyhydroxyalkanoates (PHAs) are a class of polyesters that can be naturally produced by bacteria, and one of the types of PHA, the poly(3-hydroxybutyrate) (PHB) has attracted attention for application in biomedical areas as scaffolds due to its biocompatibility and biodegradability [8]. PHB is a thermoplastic polyester classified as biopolymer, which is produced by microorganisms, as the bacteria Ralstonia eutropha, under imbalanced growth conditions [8]. The family of PHA biopolymers has been widely used for biomedical applications, such as bone plates, sutures, rivets, staples, screws, orthopedic pins, bone marrow scaffolds and meniscus regeneration devices $[9,10]$. Previous studies described the manufacturing of scaffolds based on PHB or poly(hydroxybutyrate-co-hydroxyvalerate) (PHBV) by SLS process with high porosity and controlled pore size, which are important factors for cell growth support $[2,11,12]$.

Indeed, an ideal bone substitute material should have shape and size with suitable mechanical properties to be used in sites receiving impact loading. Thus, 3D printing is an important tool for providing all these features. Moreover, materials used for bone tissue engineering should be biocompatible, osteoconductive, preferably being resorbable and replaceable by new bone formation. In general, resorbable bone substitute materials are preferred, since these materials are expected to preserve the increased bone volume during the reconstruction and simultaneously be gradually replaced by newly formed bone $[13,14]$.

Furthermore, numerous physicochemical features of scaffolds may be improved by $3 \mathrm{D}$ printing, such as surface chemistry and roughness, topography, mechanical properties and interfacial free energy (hydrophobic/hydrophilic balance). These features are also critically important to the overall biocompatibility and bioactivity (cell attachment, proliferation and differentiation) of a particular material [15-17]. Owing to the difficulties in developing efficient bioactive-alloplastic materials for printing that growth factors or drug delivery systems have been incorporated into 3D printed scaffolds [18-20]. The advantages of localized delivery are reduced therapeutic dose, controlled release pattern and negligible side effects compared with systemic drug delivery [21]. Growth factors such as vascular endothelial growth factor (VEGF), fibroblast growth factors (FGF) and bone morphogenetic proteins (BMP) are important in bone tissue engineering [4]. The osteogenic growth peptide (OGP) has attracted considerable clinical interest as a bone anabolic agent and hematopoietic stimulator [22,23].

OGP peptide is an identical sequence to the C-terminus of histone $\mathrm{H} 4$, which is physiologically present in the human and rodent serum in micromolar concentration, mainly as an OGP-OGP binding protein complex (OGP-OGPBP) and is highly and transiently increased during systemic osteogenic remodeling and post-ablation bone marrow regeneration [24]. The primary sequence of this peptide contains a highly conserved 14-amino acid motif ( $\mathrm{H}_{2} \mathrm{~N}$-ALKRQGRTLYGFGG-OH). The endogenous OGP is proteolytically cleaved after the dissociation of the OGP-OGPBP complexes, thus generating the C-terminal pentapeptide $\left(\mathrm{H}_{2} \mathrm{~N}-\mathrm{YGFGG}-\mathrm{OH}\right)$, named OGP(10-14) [25,26], which has been suggested as the physiologically active form of OGP peptide [27-29]. Gabet et al. [30] demonstrated that the systemic administration of synthetic OGP(10-14) in rats and mice increases bone formation and trabecular bone density and stimulates fracture healing. Brager et al. [31] observed in vivo the OGP(10-14) function in the regulation of the expression of type I collagen, transforming growth factors, FGF, insulinlike growth factor and aggrecan. In addition, OGP-containing biomaterials have exhibited an increase of osteoblast differentiation/activity as a result of a better bioactivity of these biomaterials and a positive effect on bone regeneration [32-35].

Tissue engineering is a promising therapeutic approach, although it is strongly limited by the difficulty of generating implants with anatomically accurate characteristics to defect, and concomitantly to have suitable conductive, inductive and mechanical properties to the tissue/ organ to be reconstituted, besides effective local drug delivery. In this context, this study investigated the production of the PHB scaffolds by 3D printing via SLS, since this technology allows an accurate printing of structures with interconnected porosity. Additionally, OGP and OGP (10-14) peptides were incorporated to the PHB scaffolds in order to increase local efficiency in the availability of bioactive molecules for inducing bone tissue repair, and might be a drug carrier system. Then, the release profile of the OGP peptide was evaluated, and the scaffolds were characterized in terms of their morphology, porosity, thermal analysis and mechanical properties. Moreover, in vitro assays were performed using mesenchymal rat bone marrow stem cells to evaluate the effect of these scaffolds with or without peptides incorporation on cellular adhesion and proliferation stages.

\section{Materials and methods}

\subsection{Scaffolds materials}

PHB was supplied by PHB Industrial S/A (Biocycle ${ }^{\circledast}$, São Paulo, Brazil) in powder form with particle size distribution in the $10-100 \mu \mathrm{m}$ range, average molecular weight of $600,000 \mathrm{Da}$ and density of $1.22 \mathrm{~g} . \mathrm{cm}^{-3}$, data reported by the PHB's supplier. The OGP, OGP (10-14) and OGP-5,6-carboxyfluorescein (OGP-CF) peptides were purchased from AminoTech@ (São Paulo, Brazil).

\subsection{Design and fabrication of $3 D$ scaffolds}

Cylindrical scaffolds model with a 3D orthogonal-projection porous architecture were designed using SolidWorks ${ }^{\circledR}$ software (Dassault Systèmes SolidWorks Corp., France). Therefore, CAD models for in vitro assays and mechanical testing were designed in the following dimensions: $11 \times 2 \mathrm{~mm}$ and $20 \times 35 \mathrm{~mm}$ (diameter $\times$ height), respectively. Struts and pores were both designed in size of $700 \mu \mathrm{m}$, which provided a porous structure with interconnected pores, as shown in Fig. 1.

The CAD models were then exported into STL file and transferred to the computer of the SLS machine. The 3D scaffolds were printed in a Sinterstation $^{\circledast} 2000$ SLS machine (3D Systems, Valencia, CA), which selectively sintered the PHB powder into scaffolds using $\mathrm{CO}_{2}$ laser. SLS process parameters for scaffold manufacturing were defined by: laser power $=8 \mathrm{~W}$; laser beam spot $=450 \mu \mathrm{m}$; laser beam speed $=2000 \mathrm{~mm} / \mathrm{s} ;$ part bed temperature $=100{ }^{\circ} \mathrm{C}$; scan spacing $=0.15 \mathrm{~mm}$; layer thickness $=0.18 \mathrm{~mm}$.

\subsection{Incorporation of peptides}

Incorporation of the peptides OGP, OGP(10-14) and OGP peptide labeled with 5,6-carboxyfluorescein (OGP-CF) was performed by adsorption. The concentration of the peptide solutions used to adsorption of the OGP peptides into scaffolds was $10^{-5} \mathrm{~mol} . \mathrm{L}^{-1}$. Therefore, the peptide solutions were prepared containing absolute ethanol/deionized water $(1: 9 ; v / v)$. The PHB scaffolds were immersed into $2 \mathrm{~mL}$ of each respective peptide solution, OGP, OGP(10-14) or OGP-CF, for $72 \mathrm{~h}$ at $10^{\circ} \mathrm{C}$. Each sample was then dried at $37^{\circ} \mathrm{C}$. Afterwards, the PHB, PHBOGP and PHB-OGP(10-14) scaffolds were sterilized by gamma 


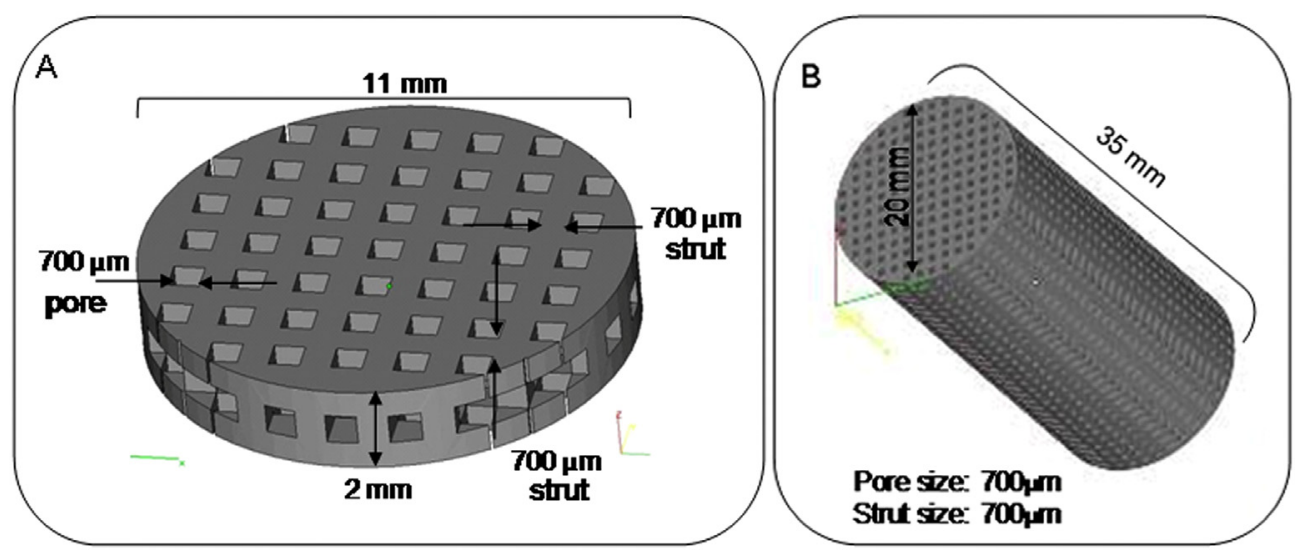

Fig. 1. Designed scaffold models using SolidWorks ${ }^{\circledast}$ for in vitro assays (A) and for mechanical testing (B).

radiation $(20 \mathrm{kGy})$ for the in vitro assays.

\subsection{Characterization of $P H B$ scaffolds}

The morphology of the PHB scaffolds was analyzed using optical (OM) and scanning electron microscopy (SEM). OM images were observed in a microscope (Leica) coupled to a digital camera (Leica DFC425). The capture of the images was performed using the Leica Application Suite software. ImageJ 1.48v software was used for measuring pore size. SEM images of the PHB scaffolds were investigated using a field emission gun scanning electron microscope (FEG-SEM; JEOL, model 7500F, USA). For in vitro assays the samples were investigated using a FEI Magellan ${ }^{\mathrm{TM}} 400 \mathrm{~L}$ microscope (FEI, USA). The samples were previously sputter coated with a $1 \mathrm{~nm}$ thick gold layer for $60 \mathrm{~s}(3 \mathrm{kV}$ and $9.5 \mathrm{~mA})$. The morphology of the PHB scaffolds was observed at an accelerating voltage of $2 \mathrm{kV}$, and the morphology of the cells was observed at an accelerating voltage of 10 up to $15 \mathrm{kV}$.

The porosity of PHB scaffolds was measured using a density kit and an electronic balance based on Archimedes' principle [36,37] according to the Eq. (1). PHB scaffolds with a size of $11 \mathrm{~mm}$ in diameter and $2 \mathrm{~mm}$ in height were used for the measurement and distilled water was used as liquid medium.

$\% \Phi=\left[1-\left(\frac{\rho_{a p p}}{\rho_{t r}}\right)\right] \times 100$

$\rho_{a p p}$ and $\rho_{t r}$ were calculated using the following Eqs. (2) and (3), after weighing the scaffold in air (dry weight, $w_{d}$ ), suspended in water $\left(w_{s}\right)$ and saturated in water $\left(w_{s a t}\right)$, respectively, and $\rho_{\mathrm{H} 2 \mathrm{O}}$ is the density of water at the test temperature. First, the dry weight of PHB scaffold was measured and the respective volume was calculated. Then, PHB scaffold was previously immersed in distilled water for $30 \mathrm{~min}$ at room temperature (RT). This time was required for filling of all the pores of scaffold with water, and for obtaining $100 \%$ swelling in relation to their dry weight. The measurements were performed in triplicate.

$\rho_{\text {app }}=\frac{\left(\rho_{H 2 O}-w_{d}\right)}{w_{s a t}-w_{s}}$

$\rho_{t r}=\frac{\left(\rho_{H 2 O}-w_{d}\right)}{w_{d}-w_{s}}$

The porosity of the designed scaffold model was calculated by obtaining the value of the total volume $\left(V_{t o t}\right)$ and the true volume $\left(V_{t r}\right)$ through Magics ${ }^{\circledR} 18.2$ software, Eq. (4).

$\% \Phi=\left[1-\left(V_{t r} / V_{t o t}\right)\right] \times 100$

Compressive tests were performed using an Instron 5569 (Instron Inc., Carton, MA, USA) with a $500 \mathrm{~N}$ load cell and a crosshead speed of $0.5 \mathrm{~mm} \cdot \mathrm{min}^{-1}$. The cylindrical samples were manufactured and tested according to ASTM F2150 and D1621, respectively. The scaffolds were tested in dry and wet conditions, in this last one scaffolds were immersed in SBF solution (simulated body fluid, Kokubo's solution) [38]. The samples were soaked in SBF solution for $10 \mathrm{~min}$ at RT for simulating the compressive strength of the scaffolds under conditions post surgical implantation. Then, the samples were laid on filter paper for removal of excess superficial water before performing the mechanical tests. At least six samples for each condition were tested. Data were expressed as mean \pm standard deviation (SD).

\subsection{OGP-CF peptide release in $S B F$ solution}

The release of labeled peptide (OGP-CF) from PHB scaffolds was monitored by fluorescence spectroscopy. The release profile was obtained by immersion of these scaffolds in $30 \mathrm{~mL}$ of SBF solution (pH 7.4) at $37^{\circ} \mathrm{C}$ under stirring at $100 \mathrm{rpm}$ and continuous flux maintained by a peristaltic pump for $72 \mathrm{~h}$. Fluorescence measurements were performed on a Varian Cary Eclipse fluorescence spectrophotometer coupled to the system using a $400-\mu \mathrm{L}$ flow-through cell with $10 \times 4 \mathrm{~mm}$ light path employing $\lambda_{\text {exc }}$ at $492 \mathrm{~nm}$ and $\lambda_{\text {em }}$ at $520 \mathrm{~nm}$; slit widths were set for a 5 -nm band-pass for all measurements. The peptide concentration was obtained from the standard curve of free-labeled peptide in SBF solution. Triplicate experiments were carried out.

\subsection{In vitro assays}

Primary mesenchymal cells from rat long bones (rat bone marrow stem cell - RBMSC) were used for all in vitro assays. Mesenchymal stem cells were isolated from bone marrow of long bones, tibia and femur following an adaptation of the protocol described by Maniatopoulos 1988 [39]. All the procedures and experiments were submitted and approved (protocol \# 32/2014) by the Ethics Committee on the Use of Animals from the School of Dentistry at Araraquara, UNESP. RBMSC were culture-expanded up to third passage with a cell density of $2 \times 10^{5}$ cells, and then seeded on scaffolds. The cells were cultured under osteogenic conditions for periods of up to 21 days using alphamininum essential medium ( $\alpha \mathrm{MEM}$, Gibco, Thermo Fisher Scientific, USA) supplemented with $10 \%$ fetal bovine serum (FBS, Gibco, Thermo Fisher Scientific, USA), $100 \mathrm{U} \cdot \mathrm{mL}^{-1}$ penicillin and $100 \mu \mathrm{g} \cdot \mathrm{mL}^{-1}$ streptomycin (Gibco, Thermo Fisher Scientific, USA), $50 \mu \mathrm{g} \cdot \mathrm{mL}^{-1}$ ascorbic acid (Sigma-Aldrich, USA) and $10 \mathrm{mmol} \cdot \mathrm{L}^{-1} \beta$-glycerophosphate (Sigma-Aldrich, USA). The culture was maintained in a humidified atmosphere with $5 \% \mathrm{CO}_{2}$. The culture medium was changed every three days. The progression of cultures was examined by phase contrast microscopy of cells grown on polystyrene.

2.6.1. Cell morphology - scanning electron microscopy (SEM)

Cell morphology and spreading were evaluated by SEM. At day 1 
and 3, cell cultures were fixed for $30 \mathrm{~min}$ at RT using glutaraldehyde $2 \%$ (Sigma-Aldrich, USA) in $\alpha$ MEM and then the samples were left immersed in glutaraldehyde $2 \%$ in $0.1 \mathrm{~mol} \cdot \mathrm{L}^{-1}$ sodium cacodylate buffer (Sigma-Aldrich, USA) (pH 7.4), overnight at RT. After, the samples were dehydrated by gradual series 25, 50, 75, 95 and $100 \%$ alcohol solutions and then dried by air vacuum. Five random images were taken from each sample using a FEI Magellan ${ }^{\mathrm{TM}} 400 \mathrm{~L}$ microscope (FEI, USA). A descriptive morphological analysis and a cell adhesion and spreading score, varying from 1 to 4 , was given to each image according to Rajaraman et al. [40].

\subsubsection{Cell proliferation assay}

Cell proliferation/viability was assessed using by a nontoxic metabolic indicator alamarBlue ${ }^{\circledR}$ kit (Life Technologies, USA). The assay indicates the cellular metabolic activity, which depends on the cell viability and on the number of cells (proliferation) in the culture. Viable cells with active metabolism reduce resazurin sodium salt into the resorufin product, which is pink and fluorescent. Briefly, at day 3, 9, 15, 18 and 21 the cell-seeded scaffolds were rinsed three times with PBS, and then fresh culture medium containing $10 \%$ alamarBlue ${ }^{\circledR}(\mathrm{v} / \mathrm{v})$ was added to each well, and cell cultures were incubated at $37^{\circ} \mathrm{C}$ for $4 \mathrm{~h}$ in an atmosphere with $5 \% \mathrm{CO}_{2}$. The dye solution (alamarBlue ${ }^{\circledR}$ :culture medium, 1:9; v/v) was used as negative control. Subsequently, absorbance of the extracted dye was measured at $570 \mathrm{~nm}$ and $600 \mathrm{~nm}$ wavelengths by an automatic microplate reader (Molecular Devices, USA), whose intensity absorbance is proportional to the number of cells attached to the scaffold. The experiments were performed triplicate for each sample.

\subsubsection{Indirect calcium precipitation assay}

The potential of the PHB scaffolds containing OGP or OGP(10-14) peptides for inducing the calcium precipitation over scaffolds was indirectly evaluated by calcium quantification into culture supernatant using Cálcio Kit (Labtest Diagnóstica, Brazil). This methodology was previously confirmed in RBMSC culture in plastic, where a reduction of calcium concentration in the culture supernatant was observed over time, consistent with the mineral formation in the plate (data not show). The assay was performed following the manufacturer's guideline, and a standard solution was used to quantify calcium present in the culture medium. At day 3, 9, 15, 18 and 21 the supernatant was collected. Calcium concentration was measured in a plate reader at $570 \mathrm{~nm}$. Cells cultured in plastic plates were used as positive control and culture media was used as negative control. Calcium precipitation on the scaffolds was considered inversely proportional to the available concentration of calcium in the supernatant.

\subsection{Statistic analysis}

Statistical analysis was performed using GraphPad Prism 5.0 software (GraphPad Software, USA). Non-parametric Kruskal-Wallis with Dunn's post-hoc test was used for comparisons among three or more groups, and Mann-Whitney was used to compare two groups. Differences were considered statistically significant when $p<0.05$.

\section{Results and discussion}

\subsection{Fabrication and characterization of the scaffolds}

The designed models were based on limitation of SLS technology, in which the correlation strut/pore directly influences in the formation of intrinsic porosity, without interconnected large pores in scaffolds. Furthermore, pore size should be enough for migration/proliferation of cells, e.g. in the case of osteoblastic cells, minimum pore size should be $300 \mu \mathrm{m}$ [36].

Fig. 2 shows printed PHB scaffold for mechanical testing and OM image. OM image shows scaffold pores decreased in size regarding to the CAD model, due to polymer concentration after processing. Pores were observed with irregular shapes and size in the 500-700 $\mu \mathrm{m}$ range.

The surface morphology of the PHB scaffolds is shown in Fig. 3. SEM images of these samples revealed that printing visa SLS allowed the formation of a favorable intrinsic porosity for cell adhesion and spreading. Moreover, the morphology of struts was well preserved and the pores could be identified and compared with the CAD model. Additionally, intact particles of polymer attached to the struts were observed without complete fusion, as is shown in Fig. 3B. This fact could be explained by the interaction of these particles to the struts due to a small amount of melting promoted by the heat generated during the SLS process [12].

The value measured to the apparent porosity of the printed scaffolds was $55.8 \pm 0.7 \%$, which was higher than the theoretical value of $40.7 \%$, calculated by Magics ${ }^{\circledR} 18.2$ software from the designed scaffold model. This high apparent porosity value may be explained by the presence of micropores on the surface and interconnect micropores into the scaffold. Similar results have been reported for printed scaffolds by SLS based on poly(hydroxybutyrate-co-hydroxyvalerate) (PHBV) and Ca-P/PHBV, which presented respectively, $64.6 \pm 2.0 \%$ and $61.8-62.6 \pm 1.2 \%$ of apparent porosity and approximately $53 \%$ of theoretical value $[37,41]$. The value of the apparent porosity observed in this study was lower than the values from the literature data. Nevertheless, this value is related to the designed CAD model, since the proportion of the printed-scaffold porosity increased in relation to the theoretical porosity, similarly to the literature data $[37,41,42]$.

The literature has demonstrated that osteogenesis in vitro is not affected by pore size, but can be enhanced by scaffolds with lower porosity [28]. However, in vivo, high porosity and pore size of at least $100 \mu \mathrm{m}$ are required, due to cell size, migration requirements and transport of nutrients; moreover, pores $>300 \mu \mathrm{m}$ are recommended to promote capillaries and new bone formation [36]. Therefore, the PHB scaffolds obtained in this study demonstrated favorable features of porosity and pore size for in vivo application and bone regeneration.

The mechanical properties as compressive strength and Young's modulus of the PHB scaffolds are shown in Table 1. The compressive properties were considered because they are important for bone tissue engineered scaffolds and should ideally match those of living bone. Although, the values measured to compressive strength of the PHB scaffolds were very lower than human cancellous bone ( $\sim 10 \mathrm{MPa})$ [43], these values were higher than the values obtained from other printed scaffolds by the SLS process even after immersion in SBF solution $[12,41]$. An important requirement for a bone scaffold for tissue engineering applications is a stiffness gradient, which mimics native bone. Therefore, scaffold porosity percentage and compressive stiffness can be formulated and compiled by mathematical relations correlating them. Considering, 3D-printed scaffolds should have a suitable pore size and porosity for cell adhesion and proliferation, having sufficient mechanical strength to temporarily support physiological loadings in vivo. Moreover, compressive strength of 3D-printed scaffolds via the SLS process is determined by raw material and mainly 3D-model geometry. Thereby, strut thickness, pore size and porosity percentage directly influences in compressive stiffness. Designed 3D model for this study (orthogonal periodic porous architecture), $0.7 \mathrm{~mm}$ pore size and $0.7 \mathrm{~mm}$ strut diameter, allowed development of printed scaffolds with a high compressive strength compared with printed Ca-P/PHBV and PHBV scaffolds, both scaffolds were manufactured using a tetragonal scaffold model with a 3D orthogonal periodic porous architecture with strut size of $0.5 \mathrm{~mm}$ and pore sizes of $0.8 \mathrm{~mm}$ [44] or $1 \mathrm{~mm}$ [12].

So far, few resorbable polymers are used to additive manufacturing by SLS technology. Thereby, one of the reasons of this work was to research more possibilities of resorbable polymers from renewable source for 3D printing via SLS technology; moreover PHB biopolymer to be a good carrier biopolymer for drug delivery [10]. On the other hand, oil-derived resorbable polyesters such as poly(caprolactone) (PCL) have been widely used to 3D printing via SLS technology [45-47]. 

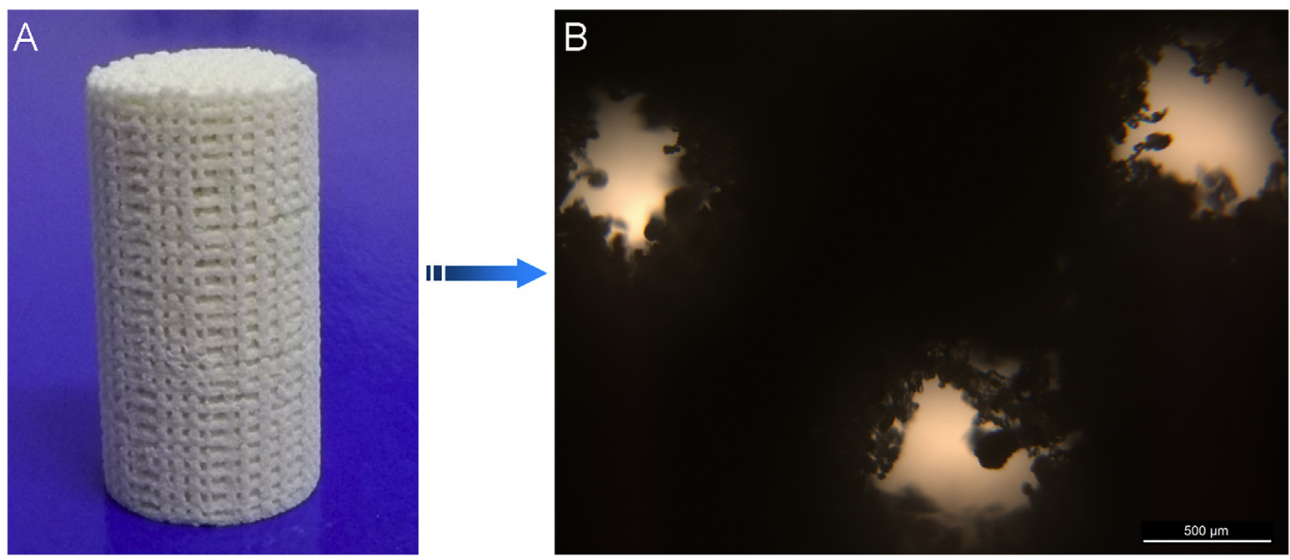

Fig. 2. (A) 3D printed scaffold via SLS. (B) OM image shows extrinsic pores of the PHB scaffolds produced by SLS processing.
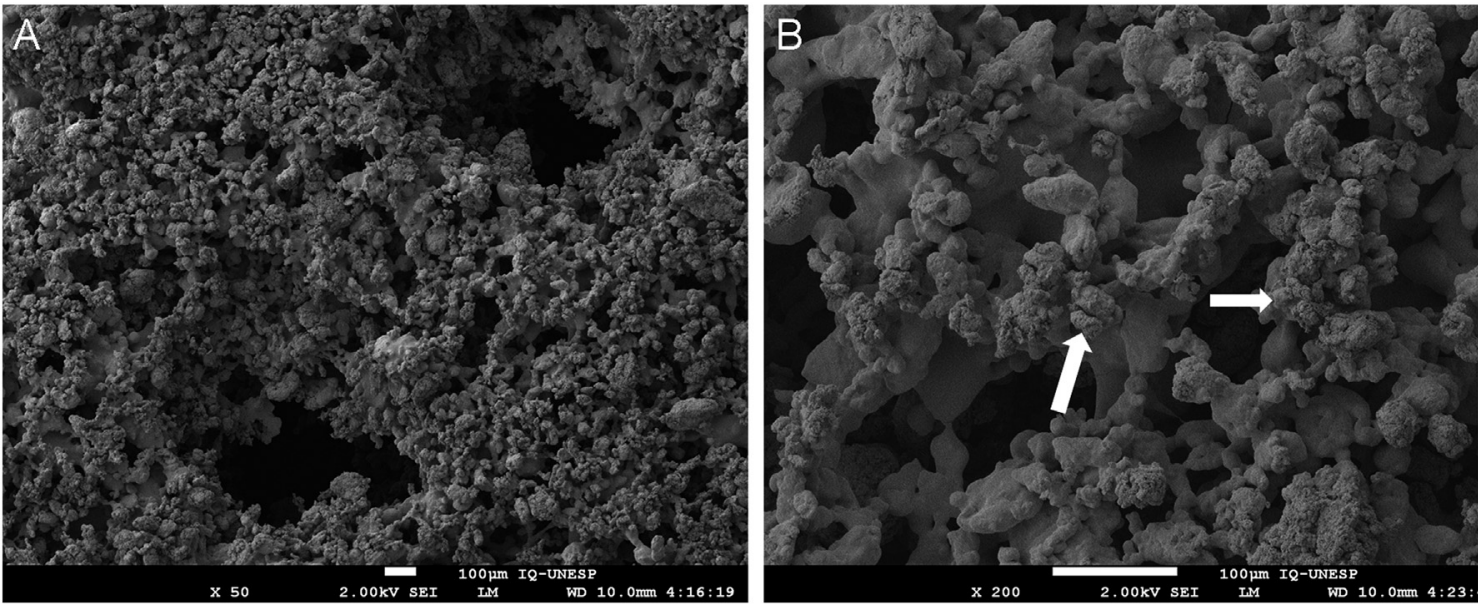

Fig. 3. SEM images of the printed PHB scaffolds. (A) magnification $50 \times$; (B) magnification $100 \times$. White arrows indicate intact PHB particles after sinterization.

Table 1

Mechanical properties of the PHB scaffolds in dry and wet conditions.

\begin{tabular}{|c|c|c|}
\hline & Compressive strength & Young's modulus \\
\hline & (MPa) & (MPa) \\
\hline PHB & $0.72 \pm 0.04$ & $4.91 \pm 0.30$ \\
\hline PHBim & $0.52 \pm 0.01$ & $3.51 \pm 0.13$ \\
\hline
\end{tabular}

The mechanical testing was obtained in dry and wet material conditions. im: after immersion in SBF solution for $30 \mathrm{~min}$. The values were indicated as mean \pm standard deviation, where $n=6$. No statistical differences with MannWhitney test.

Sudarmadji et al. (2011) [45], evaluated 3D-printed PCL scaffolds by SLS technology regarding different structural configurations and porosity. These findings revealed the three stiffest configurations consisted of struts, which were vertically oriented: hexagonal and triangular prism, octagonal and square prism and hexagonal prism. Scaffolds with vertically oriented struts, parallel to the load direction, acted as columns and could bear the compressive load better than scaffolds constructed of non-vertical struts, which failed by strut bending. Furthermore, the values to porosities, compressive stiffnesses and yield strengths varied in the ranges $40-84 \%, 2.74-55.95 \mathrm{MPa}$ and 0.17-5.03 MPa, respectively. Poly(caprolactone):hydroxyapatite (PCL:HA) composites were manufactured via SLS technology as solid gage parts and scaffolds having 1-D, 2-D and 3-D orthogonal, periodic porous architectures. The compressive effective stiffness tended to increase as the loading of HA was increased and the designed porosity was lowered. In the case of the most 3-D porous scaffold, the compressive modulus more than doubled from 14.9 to $36.2 \mathrm{MPa}$ when changing the material from 100:0 to 70:30 PCL:HA [46]. For printed $\mathrm{PCL} / \beta$-TCP scaffolds, the $\beta$-TCP concentration ( $\mathrm{wt} \%$ ) resulted in a slight increase in stiffness compared with pure PCL. $\beta$-TCP-containing scaffolds revealed a greater microporosity than the PCL scaffolds. Owing to the volume of $\beta$-TCP particles in the material to result in a lower degree of sintering. Furthermore, the incorporation of $\beta$-TCP influenced the change in material properties, in which the composites became more ductile during degradation [47].

Thereby, these 3D-printed PHB scaffolds could be potentially used for bone regeneration in regions with low load incidence, maxillofacial region, or in regions with high load incidence, but without function of load-bearing, as bone defects in femur and for spine implants; whereas, the cancellous bone microstructure has a limit to compressive strength around 0.32 to $2.25 \mathrm{MPa}[45,48]$. In addition, the fabrication approach demands a high degree of scaffold macro- and micro-architectural control in order to produce a mechanical gradient that closely mimics the native bone in a reproducible and reliable manner [45]. Thus, future studies are needed with changes in design of strut versus porosity and with addition of HA to PHB for a better analysis of macro- and micro-architectural control to a better mechanical gradient that closely mimics the bone tissue.

\subsection{Determination of OGP-CF peptide release from $P H B$ scaffolds}

The cumulative release profile versus time from the PHB/OGP-CF scaffolds is shown in Fig. 4. PHB/OGP-CF scaffolds exhibited a steady 


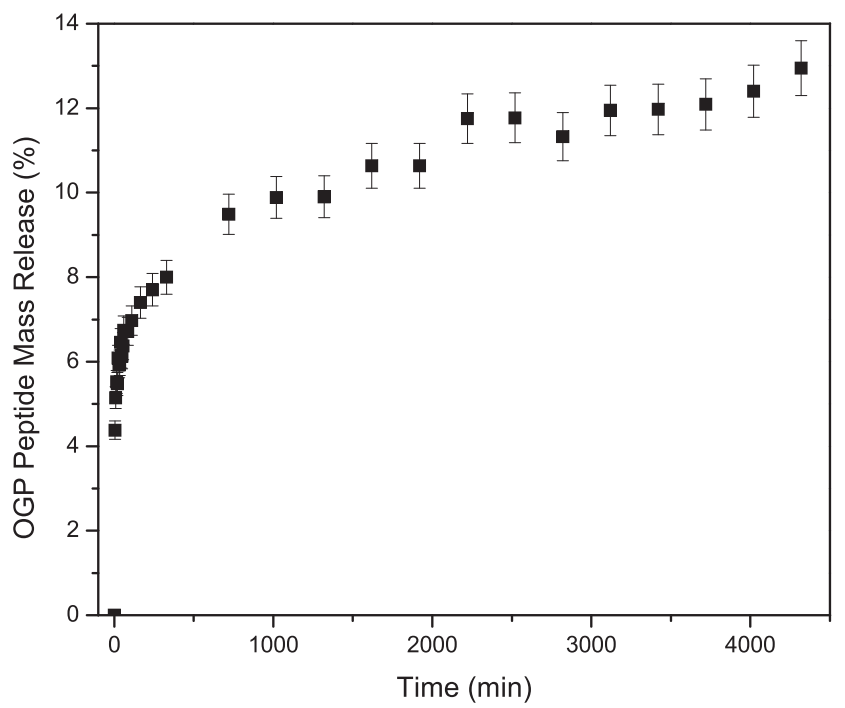

Fig. 4. OGP-CF release behavior from the PHB scaffold. Data are reported as mean \pm SD.

continued release pattern with a certain amount of initial burst release and a sustained release in the following time. This burst release observed in the first hour of experiment can be attributed to the presence of OGP-CF on the surface of the scaffolds, which can result in overestimated values in the first moments of the release test, due to swelling of the PHB scaffold within this period. At $10 \mathrm{~h}$, the amount of peptide released was in the range of $3.45 \times 10^{-6} \mathrm{~g}$, which refers to $9 \%$ of the theoretical value of the incorporated OGP-CF peptide. After this period, a steady continued release pattern was observed until $72 \mathrm{~h}$ and the amount of peptide released was around $4.87 \times 10^{-6} \mathrm{~g}$ or $8 \times 10^{-8} \mathrm{~mol} \cdot \mathrm{L}^{-1}$ (i.e., $12 \%$ of the theoretical value of the incorporated peptide). According to Bab et al. [24] and Spreafico et al. [49] the OGP peptides concentration around $10^{-8}$ up to $10^{-9} \mathrm{~mol} \cdot \mathrm{L}^{-1}$ might be considered optimal to promote a better ALP activity, and might allow a higher formation and mineralization of bone nodules. However, the released peptide concentration observed in this study suggests that this released concentration by the PHB scaffolds could be enough to favor osteoblastic cell proliferation/differentiation.

A plateau phase was not observed in this release profile, suggesting that the PHB scaffold allows a controlled release after $72 \mathrm{~h}$. According to the literature, this release behavior can be attributed to the tridimensional structure of the scaffold [50]. This release behavior is typical of a controlled release system, in which the peptide is homogeneously adsorbed on the porous surface of the material. The release occurs by diffusion of the peptide through the pores of the matrix and the diffusion rate is reduced since the diffusion distance becomes greater. The faster initial release can be explained by the fact that the OGP-CF fraction interacts with polymeric surface by weak interactions, such as van der Waals or hydrophobic interactions, wherein take place hydrophobic interactions between PHB methyl groups and hydrophobic amino acids. In addition, slight solubility of peptide can readily favor the release due to the hydrogen interactions between peptide and PHB ester groups [50-52]. The slow release after fast initial release can be suggested by the peptide incorporated into intrinsic pores of 3D structure, which interact with polymer functional groups providing a sustained effect of release, inasmuch as multiple hydrogen bonds may play a key role in the interactions between peptide and PHB in aqueous solution [50,53,54]. Indeed, PHB have been attractive for bioactive factor delivery because of their biocompatibility and degradability by hydrolysis of ester linkages [55,56]. Additionally, PHB may form supramolecular complexes with proteins via covalent bonds and multiple hydrophobic interaction sites [52].

Furthermore, this release profile of OGP-CF incorporation to the PHB scaffold was similar to OGP-CF incorporated to the mesoporous silica nanoparticles [57]. Therefore, these results corroborate to the literature, in which relates porous structures/drug delivery systems might provide a sustained effect of release $[50,53,57]$.

\subsection{In vitro assays}

The in vitro preliminary investigation using RBMSC cultures on the
A

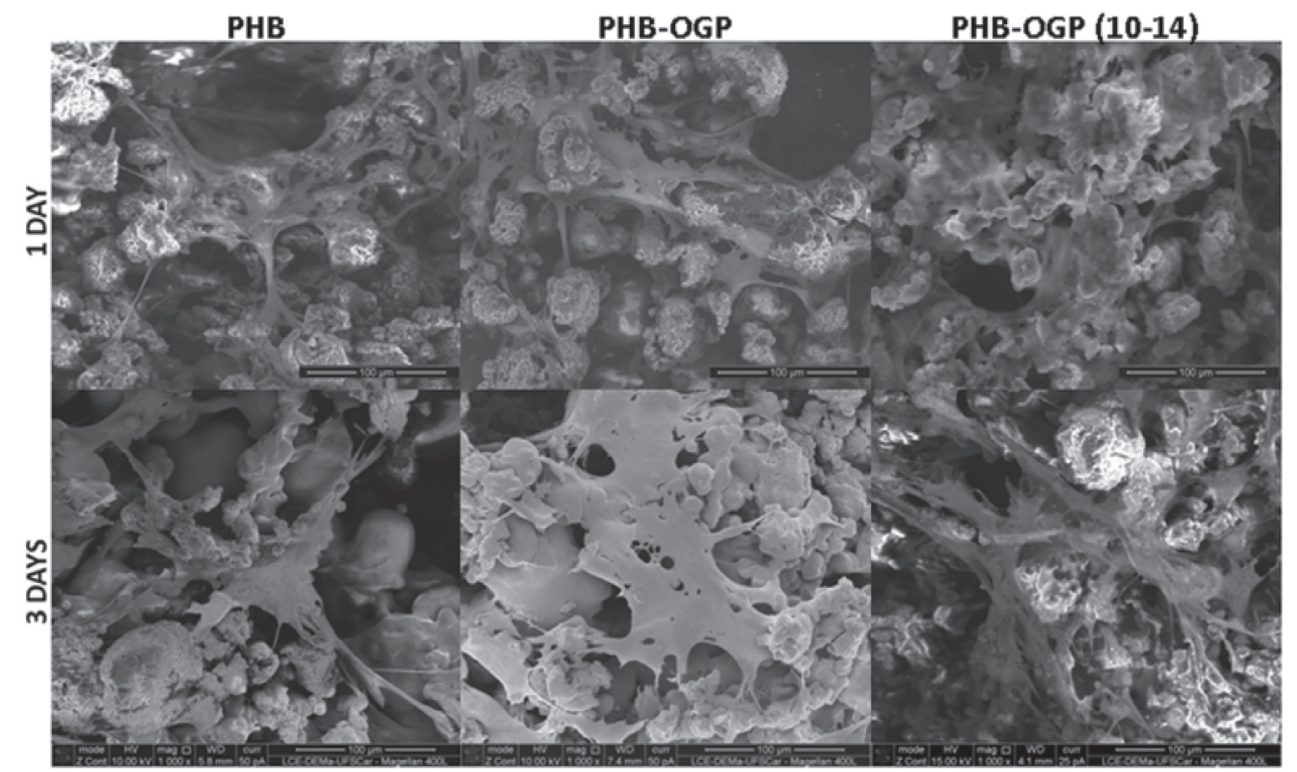

B

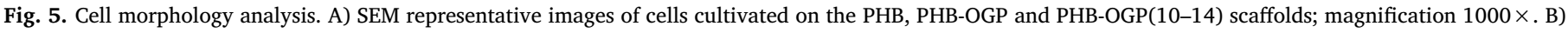
Mean and SD of scores of cell adhesion and spreading stages obtained for each group. 
3D-printed PHB scaffolds (OGP-free or OGP-containing scaffolds) revealed by SEM images well-spread polygonal cells with numerous filopodia in all groups and periods. However, in the groups containing OGP peptide, the number of cells seemed to be higher than the PHB and PHB-OGP(10-14) scaffolds, mainly at 3 days, wherein some areas presented culture confluence and multilayer areas (Fig. 5).

According to the classification of cell adhesion and spreading stages described by Rajaraman et al. [40], SEM images demonstrate cells with flattened cytoplasm and filopodia emission (stage 3) within 1 day for all groups, suggesting affinity for the materials of this study. However, in the 3 day period, we observed that the cells in the presence of OGP peptides associated with PHB scaffolds showed a more advanced cytoplasmic spreading (stage 4) compared to the cytoplasm of cells belonging to the groups of PHB and PHB-OGP(10-14) scaffolds, with significant difference.

The results from the morphological analysis by SEM showed a good cell spreading on the PHB scaffolds, mainly on scaffolds containing OGP peptide. Previous results demonstrated that PHB films stimulated a rounded osteoblast shape due to reduced spreading on this surface [58]. Therefore, the results observed in this assay suggest that the morphology, porosity and pore-size of 3D-printed PHB scaffolds by SLS technology induced cellular response and promoted cell differentiation. Indeed, surface topography influences in cellular behavior inasmuch as osteoblasts specifically adhere, proliferate and differentiate better on rougher surfaces [36].

Cell viability/proliferation revealed similar profile for all groups along the 21 days. Cell proliferation was observed in the first periods, reaching maximum values at 15 days. At this time point, PHB-OGP (10-14) scaffolds induced higher values but without significant difference with the other groups. After 15 days, cell proliferation stopped, fact that is expected after cells reach confluence and start differentiation process. A tendency to a greater response was maintained to the PHB-OGP(10-14) scaffolds compared with the other groups at 21 days. Although no statistical significance was observed (Fig. 6), these results corroborate with SEM images demonstrating cell viability and good proliferation on PHB scaffolds.

The indirect evaluation for calcium precipitation is shown in Fig. 7. Cells from all groups consumed calcium from the media in the same level, irrespective of the groups and time points. This is a limited result as no mineralization process was directly analyzed. Thus, these findings suggest that additional in vivo studies will be necessary to prove this effect and to evaluate the possible beneficial effect of OGP peptides in osteoblast differentiation and mineralized tissue formation. Considering, in vivo studies with OGP-containing different biomaterials have demonstrated that both OGP and OGP(10-14) peptides are effective for bone regeneration applications [32-35,59,60]. Shuqiang

\section{alamarBlue}

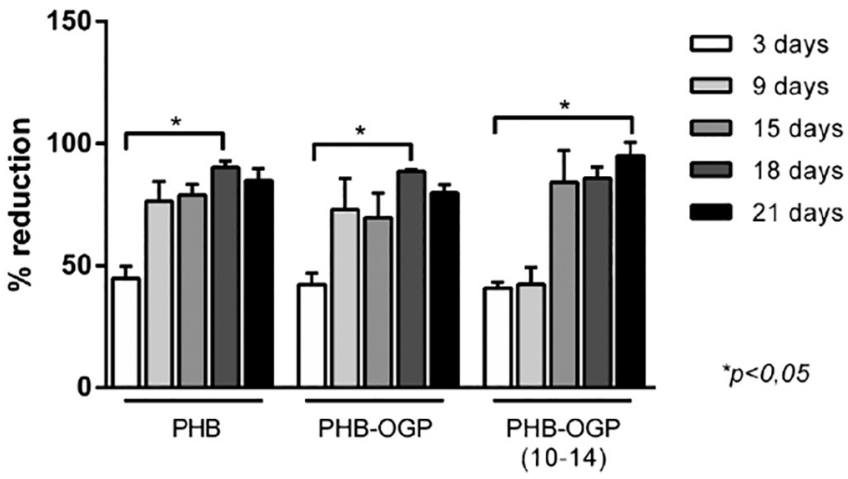

Fig. 6. Cell viability of RBMSC cultivated on PHB scaffolds with and without OGP and OGP(10-14) at day 3, 9, 15, 18 and 21.*p $<0,05$ Kruskal-Wallis and Dunn's test.

\section{Calcium quantification}

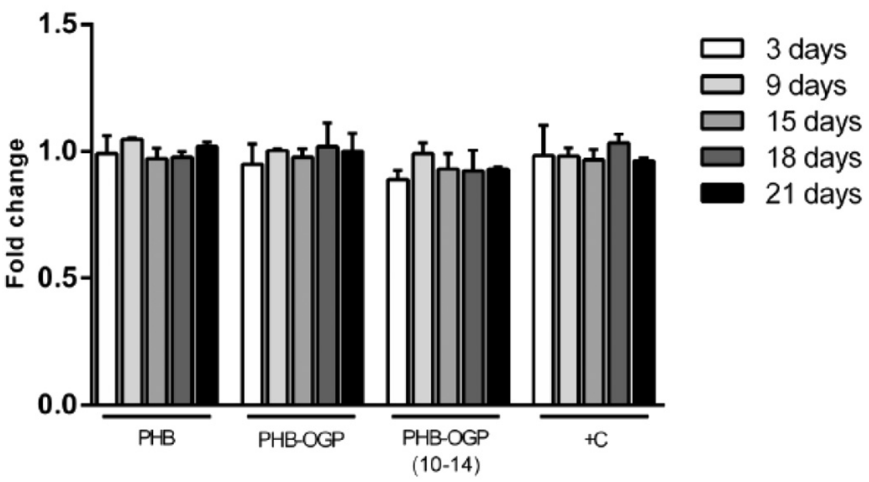

Fig. 7. Indirect evaluation for calcium precipitation in the different experimental groups at day 3, 9, 15, 18 and 21. Date normalized with negative control. No statistical differences. Kruskal-Wallis and Dunn's test.

et al. [32] demonstrated that OGP-containing PLGA scaffolds were more effective than non-OGP scaffolds for bone repair in rabbits, even though the animals from this last group had daily received OGP systemically. Additionally, OGP-functionalized poly(ester urea) scaffolds exhibited a significant tissue-scaffold integration and enhanced proliferative activity, besides promoting both osteogenic and angiogenic effects in subcutaneous rat model $[33,60]$. Another study demonstrated that injectable OGP-alginate hydrogels laden with human mesenchymal stem cells (hMSCs) was able to induce an ectopic effect with cell proliferation and mineralization an endogenous extracellular matrix [34]. Furthermore, bacterial cellulose/hydroxyapatite membranes associated with OGP or OGP(10-14) induced bone neoformation in critical-size calvarial defects mainly in early stages of bone regeneration in mice [35].

\section{Conclusions}

3D-printed PHB scaffolds with a controllable architecture and poresize were successfully manufactured by SLS technology. The printed 3D models showed geometrical and dimensional features very close to the designed 3D model. Additionally, this SLS technology allowed the sintering of a hierarchical structure with interconnected pores and intrinsic porosity with good mechanical properties. The release profile of the labeled OGP peptide from the PHB scaffolds occurred in a controlled manner, which indicated that these 3D-printed scaffolds via SLS are potential structures for drug delivery. Based on in vitro results, the PHB scaffolds favored RBMSC proliferation and viability, which is very important for the development of biomaterials. SEM analysis suggested acceleration on cell morphological differentiation in OGP incorporated group. Therefore, additional experiments are necessary to better understand possible effects of this peptide in bone formation.

\section{Funding}

This work was supported by grants from the Brazilian agencies FAPESP (Sybele Saska received scholarship, grant number: 2011/ 07947-8) and CNPq (Sidney J L Ribeiro and Sybele Saska grant number: $550414 / 2012-6)$.

\section{Competing interests}

We declare we have no competing interests.

\section{Acknowledgements}

The authors would like to thank Prof. Dr. Reinaldo Marchetto by 
spectrofluorometer facilities (Institute of Chemistry - UNESP, Brazil); and the LMA-IQ for FEG-SEM facilities.

\section{References}

[1] B. Utela, D. Storti, R. Anderson, M. Ganter, A review of process development steps for new material systems in three dimensional printing (3DP), J. Manuf. Process. 10 (2008) 96-104.

[2] T.F. Pereira, M.F. Oliveira, I.A. Maia, J.V.L. Silva, M.F. Costa, R.M.S.M. Thire, 3D printing of poly(3-hydroxybutyrate) porous structures using selective laser sintering, Macromol. Symp. 319 (2012) 64-73.

[3] A. Mazzoli, Selective laser sintering in biomedical engineering, Med. Biol. Eng. Comput. 51 (2013) 245-256.

[4] S. Bose, S. Vahabzadeh, A. Bandyopadhyay, Bone tissue engineering using 3D printing, Mater. Today 16 (2013) 496-504.

[5] M.F. Oliveira, I.A. Maia, P.Y. Noritomi, G.C. Nargi, J.V.L. Silva, B.M.P. Ferreira, E.A.R. Duek, Construção de scaffolds para engenharia tecidual utilizando prototipagem rápida, Revista Matéria 12 (2007) 373-382.

[6] X. Li, R. Cui, L. Sun, K.E. Aifantis, Y. Fan, Q. Fenh, F. Cui, F. Watari, 3D-printed biopolymers for tissue engineering application, Int. J. Polym. Sci. 2014 (2014) (13 pages).

[7] S.J. Hollister, Porous scaffold design for tissue engineering, Nat. Mater. 4 (2005) 518-524.

[8] G.Q. Chen, Q. Wu, The application of polyhydroxyalkanoates as tissue engineering materials, Biomaterials 26 (2005) 6565-6578.

[9] K. Zhao, Y. Deng, J. Chun Chen, G.Q. Chen, Polyhydroxyalkanoate (PHA) scaffolds with good mechanical properties and biocompatibility, Biomaterials 24 (2003) 1041-1045.

[10] J. Lim, M. You, J. Li, Z. Li, Emerging bone tissue engineering via Polyhydroxyalkanoate (PHA)-based scaffolds, Mater Sci Eng C Mater Biol Appl 79 (2017) 917-929.

[11] T.F. Pereira, M.A.C. Silva, M.F. Oliveira, I.A. Maia, J.V.L. Silva, M.F. Costa, R.M.S.M. Thiré, Effect of process parameters on the properties of selective laser sintered poly(3-hydroxybutyrate) scaffolds for bone tissue engineering, Virtual Phys. Prototyp. 7 (2012) 275-285.

[12] B. Duan, W.L. Cheung, M. Wang, Optimized fabrication of Ca-P/PHBV nanocomposite scaffolds via selective laser sintering for bone tissue engineering, Biofabrication 3 (1) (2011).

[13] M. Spector, Basic principles of scaffolds in tissue engineering, in: S.E. Lynch, R.E. Marx, M. Nevins, L.A. Wisner-Lynch (Eds.), Tissue Engineering: Applications in Oral and Maxillofacial Surgery and Periodontics, Quintessence Pub Co, Chicago, 2008, pp. 27-36.

[14] S. Saska, L.S. Mendes, A.M.M. Gaspar, T.S.D.O. Capote, Bone substitute materials in implant dentistry, in: I. Turkyilmaz (Ed.), Current Concepts in Dental Implantology, INTECH, 2015, pp. 158-167.

[15] P. Li, Biomimetic nano-apatite coating capable of promoting bone ingrowth, J. Biomed. Mater. Res. A 66 (2003) 79-85.

[16] R.J. Vance, D.C. Miller, A. Thapa, K.M. Haberstroh, T.J. Webster, Decreased fibroblast cell density on chemically degraded poly-lactic-co-glycolic acid, polyurethane, and polycaprolactone, Biomaterials 25 (2004) 2095-2103.

[17] H. Liu, T.J. Webster, Nanomedicine for implants: a review of studies and necessary experimental tools, Biomaterials 28 (2007) 354-369.

[18] J.H. Shim, S.E. Kim, J.Y. Park, J. Kundu, S.W. Kim, S.S. Kang, D.W. Cho, Threedimensional printing of rhBMP-2-loaded scaffolds with long-term delivery for enhanced bone regeneration in a rabbit diaphyseal defect, Tissue Eng. Part A 20 (2014) 1980-1992.

[19] J. Kundu, J.H. Shim, J. Jang, S.W. Kim, D.W. Cho, An additive manufacturing-based PCL-alginate-chondrocyte bioprinted scaffold for cartilage tissue engineering, J. Tissue Eng. Regen. Med. 9 (2015) 1286-1297.

[20] S.J. Lee, D. Lee, T.R. Yoon, H.K. Kim, H.H. Jo, J.S. Park, J.H. Lee, W.D. Kim, I.K. Kwon, S.A. Park, Surface modification of 3D-printed porous scaffolds via mussel-inspired polydopamine and effective immobilization of rhBMP-2 to promote osteogenic differentiation for bone tissue engineering, Acta Biomater. 40 (2016) $182-191$.

[21] E.K. Vorndran, U. Klammert, A. Ewald, J.E. Barralet, U. Gbureck, Simultaneous immobilization of bioactives during 3D powder of bioceramic drug release matrices, Adv. Funct. Mater. 20 (2010) 1585-1591.

[22] I. Bab, M. Chorev, Osteogenic growth peptide: from concept to drug design, Biopolymers 66 (2002) 33-48.

[23] S.C. Pigossi, M.C. Medeiros, S. Saska, J.A. Cirelli, R.M. Scarel-Caminaga, Role of osteogenic growth peptide (OGP) and OGP(10-14) in bone regeneration: a review, Int. J. Mol. Sci. 17 (11) (2016) (15 pages).

[24] I. Bab, D. Gazit, M. Chorev, A. Muhlrad, A. Shteyer, Z. Greenberg, M. Namdar, A. Kahn, Histone H4-related osteogenic growth peptide (OGP) - a novel circulating stimulator of osteoblastic activity, EMBO J. 11 (1992) 1867-1873.

[25] I. Bab, E. Smith, H. Gavish, M. Attar-Namdar, M. Chorev, Y.C. Chen, A. Muhlrad, M.J. Birnbaum, G. Stein, B. Frenkel, Biosynthesis of osteogenic growth peptide via alternative translational initiation at AUG(85) of histone H4 mRNA, J. Biol. Chem. 274 (1999) 14474-14481.

[26] I. Bab, H. Gavish, M. Namdar-Attar, A. Muhlrad, Z. Greenberg, Y. Chen, N. Mansur, A. Shteyeu, M. Chorev, Isolation of mitogenically active C-terminal truncated pentapeptide of osteogenic growth peptide from human plasma and culture medium of murine osteoblastic cells, J. Pept. Res. 54 (1999) 408-414.

[27] N. Gabarin, H. Gavish, A. Muhlrad, Y.C. Chen, M. Namdar-Attar, R.A. Nissenson,
M. Chorev, I. Bab, Mitogenic G(i) protein-MAP kinase signaling cascade in MC3T3E1 osteogenic cells: activation by C-terminal pentapeptide of osteogenic growth peptide [OGP(10-14)] and attenuation of activation by cAMP, J. Cell. Biochem. 81 (2001) 594-603.

[28] Y.C. Chen, I. Bab, N. Mansur, A. Muhlrad, A. Shteyer, M. Namdar-Attar, H. Gavish, M. Vidson, M. Chorev, Structure-bioactivity of C-terminal pentapeptide of osteogenic growth peptide [OGP(10-14)], J. Pept. Res. 56 (2000) 147-156.

[29] Y.C. Chen, A. Muhlrad, A. Shteyer, M. Vidson, I. Bab, M. Chorev, Bioactive pseudopeptidic analogues and cyclostereoisomers of osteogenic growth peptide Cterminal pentapeptide, OGP(10-14), J. Med. Chem. 45 (2002) 1624-1632.

[30] Y. Gabet, R. Muller, E. Regev, J. Sela, A. Shteyer, K. Salisbury, M. Chorev, I. Bab, Osteogenic growth peptide modulates fracture callus structural and mechanical properties, Bone 35 (2004) 65-73.

[31] M.A. Brager, M.J. Patterson, J.F. Connolly, Z. Nevo, Osteogenic growth peptide normally stimulated by blood loss and marrow ablation has local and systemic ef fects on fracture healing in rats, J. Orthop. Res. 18 (2000) 133-139.

[32] M. Shuqiang, W. Kunzheng, D. Xiaoqiang, W. Wei, Z. Mingyu, W. Daocheng, Osteogenic growth peptide incorporated into PLGA scaffolds accelerates healing of segmental long bone defects in rabbits, J. Plast. Reconstr. Aesthet. Surg. 61 (2008) 1558-1560.

[33] K.S. Stakleff, F. Lin, L.A. Smith Callahan, M.B. Wade, A. Esterle, J. Miller, M. Graham, M.L. Becker, Resorbable, amino acid-based poly(ester urea)s crosslinked with osteogenic growth peptide with enhanced mechanical properties and bioactivity, Acta Biomater. 9 (2013) 5132-5142.

[34] F.R. Maia, M. Barbosa, D.B. Gomes, N. Vale, P. Gomes, P.L. Granja, C.C. Barrias, Hydrogel depots for local co-delivery of osteoinductive peptides and mesenchyma stem cells, J. Control. Release 189 (2014) 158-168.

[35] S.C. Pigossi, G.J.P.L. De Oliveira, L.S. Finoti, R. Nepomuceno, L.C. Spolidorio, C. Rossa, S.J.L. Ribeiro, S. Saska, R.M. Scarel-Caminaga, Bacterial cellulose-hydroxyapatite composites with osteogenic growth peptide (OGP) or pentapeptide OGP on bone regeneration in critical-size calvarial defect model, J. Biomed. Mater. Res. A 103 (2015) 3397-3406.

[36] V. Karageorgiou, D. Kaplan, Porosity of 3D biomaterial scaffolds and osteogenesis, Biomaterials 26 (2005) 5474-5491.

[37] B. Duan, M. Wang, Z.Y. Li, W.C. Chan, W.W. Lu, Surface modification of threedimensional Ca-P/PHBV nanocomposite scaffolds by physical entrapment of gelatin and its in vitro biological evaluation, Front. Mater. Sci. 5 (2011) 57-68.

[38] T. Kokubo, H. Kushitani, S. Sakka, T. Kitsugi, T. Yamamuro, Solutions able to reproduce in vivo surface-structure change in bioactive glass-ceramic A-W, J. Biomed. Mater. Res. A 24 (1990) 721-734.

[39] C. Maniatopoulos, J. Sodek, A.H. Melcher, Bone formation in vitro by stromal cells obtained from bone marrow of young adult rats, Cell Tissue Res. 254 (1988) 317-330.

[40] R. Rajaraman, D.E. Rounds, S.P. Yen, A. Rembaum, A scanning electron microscope study of cell adhesion and spreading in vitro, Exp. Cell Res. 88 (1974) 327-339.

[41] B. Duan, M. Wang, W.Y. Zhou, W.L. Cheung, Z.Y. Li, W.W. Lu, Three-dimensional nanocomposite scaffolds fabricated via selective laser sintering for bone tissue en gineering, Acta Biomater. 6 (2010) 4495-4505.

[42] B. Duan, M. Wang, Customized Ca-P/PHBV nanocomposite scaffolds for bone tissue engineering: design, fabrication, surface modification and sustained release of growth factor, J. R. Soc. Interface 5 (2010) S615-29.

[43] B.B. Mandal, A. Grinberg, E.S. Gil, B. Panilaitis, D.L. Kaplan, High-strength silk protein scaffolds for bone repair, Proc. Natl. Acad. Sci. U. S. A. 109 (2012) 7699-7704.

[44] B. Duan, M. Wang, W.Y. Zhou, W.L. Cheung, Z.Y. Li, W.W. Lu, Three-dimensiona nanocomposite scaffolds fabricated via selective laser sintering for bone tissue engineering, Acta Biomater. 6 (2010) 4495-4505.

[45] N. Sudarmadji, J.Y. Tan, K.F. Leong, C.K. Chua, Y.T. Loh, Investigation of the mechanical properties and porosity relationships in selective laser-sintered polyhedral for functionally graded scaffolds, Acta Biomater. 7 (2011) 530-537.

[46] S. Eshraghi, S. Das, Micromechanical finite-element modeling and experimental characterization of the compressive mechanical properties of polycaprolactonehydroxyapatite composite scaffolds prepared by selective laser sintering for bone tissue engineering, Acta Biomater. 8 (2012) 3138-3143.

[47] H. Doyle, S. Lohfeld, P. McHugh, Evaluating the effect of increasing ceramic content on the mechanical properties, material microstructure and degradation of selective laser sintered polycaprolactone/beta-tricalcium phosphate materials, Med. Eng. Phys. 37 (2015) 767-776.

[48] A. Nazarian, M. Stauber, D. Zurakowski, B.D. Snyder, R. Muller, The interaction of microstructure and volume fraction in predicting failure in cancellous bone, Bone 39 (2006) 1196-1202.

[49] A. Spreafico, B. Frediani, C. Capperucci, A. Leonini, D. Gambera, P. Ferrata, S. Rosini, A. Di Stefano, M. Galeazzi, R. Marcolongo, Osteogenic growth peptide effects on primary human osteoblast cultures: potential relevance for the treatment of glucocorticoid-induced osteoporosis, J. Cell. Biochem. 98 (2006) 1007-1020.

[50] V. Karavelidis, E. Karavas, D. Giliopoulos, S. Papadimitriou, D. Bikiaris, Evaluating the effects of crystallinity in new biocompatible polyester nanocarriers on drug release behavior, Int. J. Nanomedicine 6 (2011) 3021-3032.

[51] A. Sousa, K.C. Souza, E.M. Sousa, Mesoporous silica/apatite nanocomposite: special synthesis route to control local drug delivery, Acta Biomater. 4 (2008) 671-679.

[52] C. Cao, Y. Yudin, Y. Bikard, W. Chen, T. Liu, H. Li, D. Jendrossek, A. Cohen, E. Pavlov, T. Rohacs, E. Zakharian, Polyester modification of the mammalian TRPM8 channel protein: implications for structure and function, Cell Rep. 4 (2013) 302-315

[53] M.J. Lawrence, G.D. Rees, Microemulsion-based media as novel drug delivery systems, Adv. Drug Deliv. Rev. 45 (2000) 89-121. 
[54] H. Lodish, A. Berk, S.L. Zipursky, P. Matsudaira, D.D.J. Baltimore, Noncovalent bonds, in: H. Lodish, A. Berk, S.L. Zipursky, P. Matsudaira, Baltimore DDJ (Eds.), Molecular Cell Biology, Freeman, W. H. \& Company, New York, 2000.

[55] X.J. Loh, S.H. Goh, J. Li, Hydrolytic degradation and protein release studies of thermogelling polyurethane copolymers consisting of poly[(R)-3-hydroxybutyrate], poly(ethylene glycol), and poly(propylene glycol), Biomaterials 28 (2007) 4113-4123.

[56] M.K. Nguyen, E. Alsberg, Bioactive factor delivery strategies from engineered polymer hydrogels for therapeutic medicine, Prog. Polym. Sci. 39 (2014) $1236-1265$

[57] L.S. Mendes, S. Saska, M.A.U. Martines, R. Marchetto, Nanostructured materials based on mesoporous silica and mesoporous silica/apatite as osteogenic growth peptide carriers, Mater Sci Eng C Mater Biol Appl 33 (2013) 4427-4434.
[58] B. Nebe, C. Forster, H. Pommerenke, G. Fulda, D. Behrend, U. Bernewski, K.P. Schmitz, J. Rychly, Structural alterations of adhesion mediating components in cells cultured on poly-beta-hydroxy butyric acid, Biomaterials 22 (2001) 2425-2434.

[59] S. Saska, R.M. Scarel-Caminaga, L.N. Teixeira, L.P. Franchi, R.A. dos Santos, A.M. Minarelli Gaspar, P.T. de Oliveira, A.L. Rosa, C.S. Takahashi, Y. Messaddeq, S.J. Lima Ribeiro, R. Marchetto, Characterization and in vitro evaluation of bacterial cellulose membranes functionalized with osteogenic growth peptide for bone tissue engineering, J. Mater. Sci. Mater. Med. 23 (2012) 2253-2266.

[60] G.M. Policastro, F. Lin, L.A. Smith Callahan, A. Esterle, M. Graham, K. Sloan Stakleff, M.L. Becker, OGP functionalized phenylalanine-based poly(ester urea) for enhancing osteoinductive potential of human mesenchymal stem cells, Biomacromolecules 16 (2015) 1358-1371. 